\title{
STUDY ON APPLICATION OF HIGH SPEED MILLING IN DIES MANUFACTURING FOR PLATE HEAT EXCHANGERS
}

\author{
Xiaoyang Wang ${ }^{1}$, Limin $\mathrm{Li}^{2}$ \\ ${ }^{\prime}$ School of Mechatronics Engineering \& Automation, Shanghai University, China; Email: \\ wangxiaoyang1997@126.com ${ }^{2}$ CIMS \& Robot Center of Shanghai University, Shanghai \\ University, China.
}

\begin{abstract}
This paper studies the application strategies of high speed milling (HSM) technology in dies manufacturing for plate heat exchangers (PHE) according to the features of dies for plate heat exchangers (DPHE). It mainly analyzes the safety strategy, the using strategy of cutting tools, the technics, the virtual reality and simulation and so on under HSM situation, which is very significance for promoting deep application of HSM technology in industrial enterprises and improving aggregate level of our manufacturing industry.
\end{abstract}

Key words: High Speed Milling; HSM strategy; Dies for Plate Heat Exchangers; Technics.

\section{INTRODUCTION}

High speed milling (HSM) technology is one kind of emerging advanced manufacturing technologies (AMT), which results from the integrated application and development of many new technologies, such as new material technology, computer technology, control technology, precision manufacturing and so on. HSM technology refers to a system, as shown in Fig. 1. HSM technology has more superiority than low speed milling, for example, greatly increasing the material cutting ratio per unit time, getting to much smooth surface quality, successfully machining high rigidity materials. Since the early 1990s, with the maturing of high-speed numerical control machine tools technique and cutting tools technique, HSM Technics has increasingly become the key technique to make successfully high speed milling. In the recent past, application of HSM in difficult-to-machine

Please use the following format when citing this chapter:

Wang, Xiaoyang, Li, Limin, 2006, in International Federation for Information Processing (IFIP), Volume 207, Knowledge Enterprise: Intelligent Strategies In Product Design, Manufacturing, and Management, eds. K. Wang, Kovacs G., Wozny M., Fang M., (Boston: Springer), pp. 743-748. 
materials and complicated shapes is more and more extensive. And dies for plate heat exchangers (DPHE) are one of the complicated shapes. Due to the big size and complicated shape of plate and present low velocity machining which results in poor surface quality only to be improved by hand-grinding, the whole time is very long which limits the development of plate heat exchangers. Hence, it is very significant to shorten the machining time and improve its surface quality by adopting HSM technology in dies manufacturing for plate heat exchangers (PHE).

Based on the key technology of HSM, aimed at the features of DPHE, the paper studies the technics strategy of HSM in dies manufacturing for PHE. The practice indicates adopting high speed milling is not only the effective method to dies manufacturing for PHE but also the best choice to large and difficult-to-machine work piece.

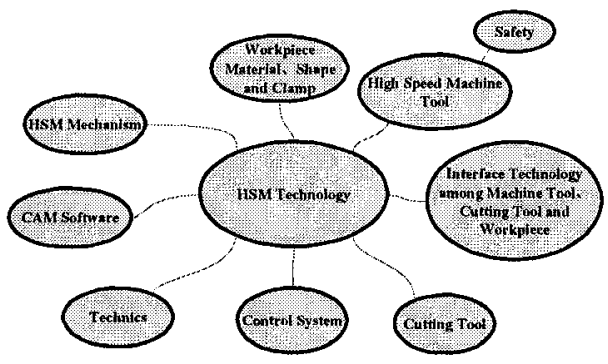

Figure 1. High Speed Milling System

\section{SUMMARIZING OF HSM TECHNOLOGY}

HSM refers to milling in much high speed than conventional milling speed. Therefore, sometimes it is called Ultra-High Speed Milling.

Through ultra-high speed simulation test, Dr. Carl Salomon (Germany's cutting physicist) found that cutting temperature increases with the increasing cutting speed within conventional cutting speed. There exists a speed scope for every work piece material in which cutting is impossible because cutting temperature is too high to withstand for any cutting tool. However, cutting temperature will reduce when cutting speed continues increasing and exceeds such a speed scope. At the same time, cutting force also drops greatly. In other words, there will be lower cutting temperature and lower cutting force within some high cutting speed scope. We can not only make ultra-high speed cutting with existing tools which will reduce 
cutting time sharply and improve producing efficiency of machine tool greatly, but also bring a series of fine characteristics into cutting process [1].

During the early 1990s, application of Motor-spindles technique and Linear-motor technique in machine tools, it has realized high speed some up to $60000 \sim 100000 \mathrm{r} / \mathrm{min}$, reached high feed rate and high fast-stroke speed up to $60 \sim 100 \mathrm{~m} / \mathrm{min}$ and obtained high acceleration/deceleration of spindle and table, from past $0.1 \mathrm{~g} \sim 0.2 \mathrm{~g}$ to now $1 \mathrm{~g} \sim 8 \mathrm{~g}$, which makes speed transition finished instantly.

HSM technics technology is one of the key technologies to make successfully high speed milling, including selecting different milling methods aiming at different materials, optimizing machining parameters and selecting appropriate cutting tool materials and cutting tool parameters.

\section{FEATURES OF DPHE}

PHE is usually composed of corrugating and concavo-convex metallic plates touched each other. It can exchange heat sufficiently because of no bypass in the heat transferring. Corrugation makes fluid turbulently flow. So its heat exchange coefficient is very high. DPHE is the key equipment to produce plates and is one kind of high-precision dies. Our study concentrates in the cores' milling. The core material of DPHE is the $40 \mathrm{Cr}$, which corrugates the stainless steel plates with thickness $0.6 \sim 0.8 \mathrm{~mm}$, as shown in Fig. 2. DPHE mainly has the following features:

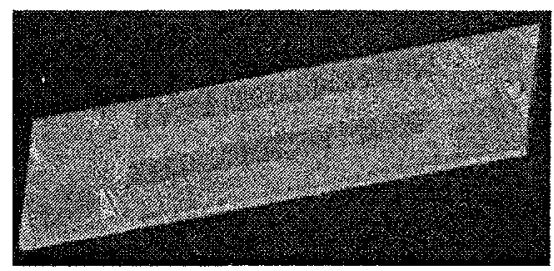

Figure 2. Dies Cores of Forming Plate

(1) Big outline dimensions: The die core area is generally above $1 \mathrm{~m}^{2}$. Some even achieve above $1.5 \mathrm{~m}^{2}$.

(2) Small contact point sizes: Plate often adopts small sizes in need of heat exchanging and intensity. Minimal end size is generally between $2.5 \mathrm{~mm}$ and $6 \mathrm{~mm}$. 
(3) Changeful corrugation angles: There are three angles around sealed groove between degree 25 to 45 . So different angle surfaces mutually pass through that is difficult to milling.

(4) Small corrugation depth: The corrugation is usually about $3.5 \mathrm{~mm}$.

(5) High request for size precision: Dies corrugates the stainless steel plates with thickness 0.6 to $0.8 \mathrm{~mm}$. After corrugating, shape depth deviation and sealed groove size deviation does not surpass $\pm 0.10 \mathrm{~mm}$.

(6) High surface quality: Obvious tool tracks can't be on the formation surfaces of die cores because the mediums that plates transmit are corrosive that request corrugating plates have much high surface precision which is not allowed depth $0.05 \mathrm{~mm}$ upwards pits, scratches or indentation on surfaces.

\section{HSM STRATEGY OF DPHE}

The particular structure and the special request decide that only HSM can obtain the high production efficiency and the high surface quality. The cores of DPHE have so massive light-sized machining surfaces and the neighboring incline angles are so different that it is necessary to adopt small diameter cutting tools and very high spindle rotational speed. But then, it is possible to select small cutting depth value because the total depth is only $3.5 \mathrm{~mm}$. The key is optimizing the cutting tool path and other machining parameters to avoid that cutting quantity changes sharply when milling work piece. In practice, it should mainly use the following machining strategies:

(1) Safety strategy

Most of cutting tools in HSM are end milling tools and face milling tools whose centrifugal forces surpass greatly cutting force when the tools are in high speed rotating. So the first important thing when adopting HSM is safety because accident would bring great injury and loss to person and machine tools. The safety strategy is that the machining parameters never exceed the rotation speed and correlative characteristic parameters that cutting tools allow.

(2) Using strategy of cutting tools

Using coated cemented carbide is the best choice because the cutting is not steady especially when machining the head plate die cores. Cutting tools should be high wear-resisting, high toughness and high anti- impact. Coated cemented carbide tools have high heat-resist and resistance to wear, as well as good toughness and anti- impact.

(3) Rough machining technics

Surface quality and outline precision is not especially important during rough machining. This moment, tools attrition is most important because it is very difficult to achieve the stable cutting condition. Considering machining 
efficiency and cutting tool life, it is much important to keep even cutting quantity, constant cutting direction and linear speed, good transient equilibrium. Simultaneously maintain climbing by any possibility.

From the above, when rough machining: (a) maintain stable cutting depth and quite small undulation scope cutting width; (b) add filleting transition at tool path corner; (c) feed tool along spiral line or maximal angle $5^{\circ}$ oblique line when machining the interior part of work piece.

(4) Half-finish machining technics

Half-finish machining is mainly to retain a certain working allowance for finish machining. The main task of this process is to smooth the sharp corner and get rid of surplus material. At present majority CAM software can automatically identify rest material and create cleaner tool path. Therefore, this process mainly confirms the results of clearing corner and cutting allowance to retain even milling allowance for finish machining.

(5) Finish machining technics

Finish machining is the last step of procedure. Its goal is to meet the requirements for best surface quality and outline precision. Too high cutting speed, too small federate per tooth ( $\mathrm{fz}$ ) or unstable allowance can cause coating layer burning and destroy the material. Therefore, when finish machining: (a) avoiding turning sharply; (b) reach next cutting depth directly from contour in order to avoid outside feeding or retracting operation. If feeding or retracting outside, then feed or retract along spiral line or oblique line. (c) fz should be suit for radial cutting depth (ae); (d) select stable fz to get requesting surface quality and maximum tool life.

(6) Virtual reality and simulation

Small sizes of corrugation contact points and consecutive concaveconvex shapes cause frequently over-cut and no-cut phenomenon. It is important to make full use of the simulation function of advanced CAM software and inspect carefully tool path.

\section{COMPARISON OF HSM AND CONVENTION MILLING}

It takes about four to seven months with convention milling method to machine DPHE. Moreover the surface quality does not satisfy the product requirement only to be improved by hand grinding. Big outline size and small concave-convex shapes make hand-grinding very difficult and taking time. However, there will be the following superiorities if using HSM:

(1) With cutting speed increasing greatly, feed speed improves about five to ten times and material cutting ratio per unit time enhances three to six 
times than conventional method. It reduces greatly idle motion time of nocut operation because its speed increases a lot. As a result, the efficiency of machine tools increases about four times.

(2) The exciting frequency is so high in HSM that is far away from the inherent frequency of machine-tool-part. So machine working is steady with light vibration and surface is the same as grinding surface.

(3) Cutting force may reduce above $30 \%$, and about $95 \% \sim 98 \%$ cutting heat is taken away by chip before it is transmitted to work piece. Therefore, work piece can basically maintain cold state all milling long, no distortion, no case hardening.

(4) HSM can cut many kinds of difficult-to-machine materials. It can mill the blade shapes of bordering-ornament blanking dies for PHE after quencher, which can avoid the distortion that heat treatment brings and which also resolves the problem of blade sharpening.

(5) High speed machine tools can bring quick return on its investment by shortening time of delivery and reducing floor space and the number of staff.

\section{CONCLUSION}

HSM technology would have become a kind of general and foundation technology of advanced manufacturing technology. It represents the development direction to cutting technology and has widespread application prospect. HSM can substitute for hand grinding in dies manufacturing for PHE. Its successful application will improve the production efficiency and surface quality, shorten machining period, and enhance the level of DPHE technology and the ability of quick reaction to marketplace. It is important to impel application of HSM in difficult-to-machine structure and shape. It is also important to develop our country HSM technology and improve application level of high speed machining and develop advanced manufacturing technologies. Realizing HSM needs to integrate and optimize many foundation subjects and implement systems engineering technology.

\section{REFERENCES}

1. Bailin Zhang. High Speed Machining Technology and Application. Beijing: Machine Press.2002.9

2. Eing-Jer Wei, Ming-Chang Lin. Study on general analytical method for CNC machining the free-form surfaces. Journal of Materials Processing Technology 168 (2005) 408-413 